\title{
Kernos
}

Revue internationale et pluridisciplinaire de religion grecque antique

$22 \mid 2009$

Varia

\section{Pierre Sineux, Amphiaraos. Guerrier, devin et guérisseur}

\section{Aurian Delli Pizzi}

\section{OpenEdition \\ Journals}

Édition électronique

URL : http://journals.openedition.org/kernos/1799

DOI : 10.4000/kernos.1799

ISSN : 2034-7871

\section{Éditeur}

Centre international d'étude de la religion grecque antique

\section{Édition imprimée}

Date de publication : 1 janvier 2009

Pagination : 322-325

ISSN : 0776-3824

\section{Référence électronique}

Aurian Delli Pizzi, «Pierre Sineux, Amphiaraos. Guerrier, devin et quérisseur », Kernos [En ligne], 22 |

2009, mis en ligne le 15 septembre 2011, consulté le 21 septembre 2020. URL : http://

journals.openedition.org/kernos/1799; DOI : https://doi.org/10.4000/kernos.1799

Ce document a été généré automatiquement le 21 septembre 2020.

Kernos 


\title{
Pierre Sineux, Amphiaraos. Guerrier, devin et guérisseur
}

\author{
Aurian Delli Pizzi
}

\section{RÉFÉRENCE}

Pierre SINEUX, Amphiaraos. Guerrier, devin et guérisseur, Paris, Les Belles Lettres, 2007. 1 vol. 15 䜿 $21,5 \mathrm{~cm}, 276$ p. (Vérité des mythes). ISBN : 978-2-251-32441-8.

1 Le nom d'Amphiaraos évoque divers motifs : guerrier englouti sous les murs de Thèbes lors de l'expédition des Sept, devin qui rend des oracles, divinité guérisseuse, etc. Cet ouvrage entreprend une étude globale de toutes les facettes, aussi bien mythiques que rituelles, de ce personnage multiple. Néanmoins, l'A. signale d'emblée que son but n'est pas de proposer une image cohérente et exhaustive, mais bien un ensemble d'éléments significatifs et de relations entre Amphiaraos et son environnement (dieux, hommes, sanctuaire). En matière de culte, c'est principalement le sanctuaire d'Oropos, territoire à la limite entre la Béotie et l'Attique, qui est envisagé. Le postulat de l'A. est que toutes les données de la figure d'Amphiaraos sont à prendre en considération pour expliquer l'introduction de son culte dans ledit sanctuaire : on ne peut se contenter d'alléguer des besoins religieux nouveaux, issus des troubles de la guerre du Péloponnèse, comme le laisse entendre Thucydide. Enfin, en s'intéressant à la relation que les hommes établissent avec la divinité à travers le rituel, l'A. veut montrer que lecas «Amphiaraos » présente des similitudes avec le culte d'Asclépios et, plus largement, permet d'éclairer différentes pratiques du système religieux grec (incubation, démarche sacrificielle, etc.).

2 Le mythe auquel se rattache Amphiaraos fait l'objet du premier chapitre. Différentes traditions montrent le héros régnant sur Argos, dans une lutte pour le pouvoir avec les Talaïdes. Au terme d'un accord conclu avec Adraste, Amphiaraos doit épouser la sœur de celui-ci, Eriphylè, laquelle détiendra à l'avenir un pouvoir d'arbitrage entre les deux parties. À l'arrivée de Polynice, Amphiaraos est contraint par son épouse corrompue de 
prendre part à l'expédition contre Thèbes, bien qu'il soit conscient de l'issue funeste de ce départ, grâce à la tekhnè mantikè qu'il détient. L'A. nous livre une description de plusieurs documents iconographiques présentant le motif du départ. Les Tragiques ont également exploité ces épisodes du cycle épique, en laissant d'Amphiaraos l'image d'un guerrier excellent, qui se distingue par sa sagesse et sa piété, et ne partage pas l'hubris de ses pairs.

3 Le chapitre 2 examine la double identité, héroïque et divine, du personnage. Le motif de sa disparition - il est englouti sous la terre par Zeus pour échapper à une mort déshonorante lors du combat - est étudié à travers la littérature et l'iconographie. Cet engloutissement constitue une promotion pour le lieu de la disparition et fournit un aition à l'existence d'un culte vraisemblablement antérieur à celui d'Oropos. Selon Pausanias, c'est à Oropos qu'Amphiaraos, devenu dieu, aurait ensuite fait son anodos. Bien qu'il ne soit pas facile de le déterminer, l'A. conclut, au terme d'une argumentation détaillée, que le culte d'Amphiaraos aurait fait son apparition à Oropos autour de 420 av. J.-C., en tant que divinité.

Le chapitre 3 se concentre sur le contexte proprement historique de l'installation de ce culte à Oropos et examine dans quelle mesure celui-ci a permis à Athènes de consolider son pouvoir sur ce territoire. Dans les Suppliantes d'Euripide, pièce qui témoigne clairement du sentiment anti-thébain d'Athènes à l'époque, Thésée exalte la grandeur d'Amphiaraos. Selon l'A., c'est bien la marque que, par un ajustement du fonds légendaire, les Athéniens cherchaient à s'approprier une partie de la destinée des Sept contre Thèbes. Dès lors, l'introduction à la même époque du culte à Oropos, alors territoire athénien, n'est sans doute pas anodine. Ce sanctuaire est vraisemblablement devenu un des lieux où l'exaltation patriotique athénienne s'exprimait avec le plus de vigueur : il suffit d'examiner le Pour Euxénippos d'Hypéride, qui fait état d'un différend concernant la répartition des collines d'Oropos entre les tribus athéniennes, et le passage d'éphèbes athéniens au cours du IV siècle, pour s'en rendre compte. D'autre part, les sources épigraphiques, relativement abondantes sur le sujet, permettent également de mesurer l'importance accordée par les Athéniens au sanctuaire d'Oropos, à chaque fois que celui-ci se trouvait en leur possession (décrets réglant la vie du sanctuaire, décret de Pandios, etc.). Quant à l'implantation du culte d'Amphiaraos à Rhamnonte, forteresse qui a constitué un atout important pour les Athéniens lors de la guerre du Péloponnèse, elle illustre également le rôle joué par le dieu/héros dans la défense du territoire attique.

5 Au chapitre 4, l'A. étudie la séquence des gestes et des comportements préliminaires à l'accomplissement de l'incubation au sanctuaire d'Oropos, et les similitudes et divergences que celle-ci présente par rapport au culte d'Asclépios. Il est tout d'abord fait mention des abstinences : pratique du jeûne, attestée à Oropos à l'époque impériale, et interdits du vin, des fèves et des lentilles dès le début de l'histoire du culte, ce qui pose la question d'une éventuelle influence pythagoricienne. Les différents usages de l'eau amènent l'A. à examiner la disposition du sanctuaire, d'après les vestiges archéologiques. Le rituel sacrificiel est également étudié, ce qui permet de voir les rapports entre Amphiaraos et d'autres divinités au sein de son sanctuaire. Enfin, il est question du versement de l'éparkhè, partie intégrante du processus de consultation du dieu qui se faisait sous le contrôle du néocore.

Le chapitre 5 porte sur la place de l'incubation au sein du rituel. Envisageant d'abord son organisation pratique, l'A. décrit la séparation des sexes ainsi que les koimètèria qui 
se sont succédé dans le temps, pour conclure que le rite de l'incubation n'était pas associé à une forme architecturale précise. D'autre part, la confrontation des documents iconographiques avec le témoignage de Pausanias pose de nombreuses interrogations, concernant notamment le sacrifice d'un bélier sur la peau duquel le consultant devait passer la nuit. Il est ensuite question des sacrifices et des offrandes d'action de grâce, à travers l'examen de différents reliefs votifs et de listes d'offrandes.

7 Enfin, le chapitre 6 s'interroge sur l'image que les Anciens se faisaient de la rencontre avec la divinité à travers le rêve. À Oropos, c'est principalement en tant que guérisseur qu'Amphiaraos apparaît : se pose alors la question des causes d'un déclin éventuel de la fonction oraculaire présente auparavant en Béotie et du développement de la fonction guérisseuse. En réalité, la dimension oraculaire du personnage existait toujours à travers l'incubation mais restait secondaire, comme le montre la consultation à but politique d'Euxénippos, qui illustre les limites de l'oracle d'Amphiaraos et la supériorité de l'oracle delphique : le message divin n'étant révélé en rêve qu'à un seul individu, il est source de contestations. Ceci n'a pas empêché, en terme de représentation, le rapprochement entre Amphiaraos et Apollon. Ensuite, les témoignages, principalement iconographiques, de l'exercice de la fonction guérisseuse d'Amphiaraos soulèvent évidemment la question des rapports avec Asclépios. Il semblerait que, malgré des similitudes iconographiques très grandes, les divinités semblables auxquelles Amphiaraos et Asclépios étaient associés, et le développement parallèle du sanctuaire d'Oropos et du sanctuaire d'Asclépios à Athènes, les Anciens ne les aient jamais totalement assimilés, dans la mesure où leur nom restait un élément distinctif.

8 Comme P. Sineux le souligne dans sa conclusion, l'étude d'une figure aussi complexe que celle d'Amphiaraos nous oblige à dépasser les catégories que nous utilisons habituellement pour appréhender la religion des Grecs et à ne pas nous enfermer dans une perspective trop étroite, qui n'envisagerait pas, entre autres, la dimension politique du culte. La vision de l'A. s'avère tout à fait recevable, mais non sans limites. Par exemple, mettre en relation toutes les données entourant le personnage et son culte permet certes d'éclairer le fonctionnement du sanctuaire, ainsi que les enjeux qui y sont liés, mais n'offre pas de réponse claire quant à l'origine et l'évolution de celui-ci à ses débuts. D'où l'incohérence suivante, relative à l'apparition de la fonction guérisseuse à Oropos : pourquoi minimiser le rôle de «besoins religieux nouveaux pour expliquer tout aussi bien l'introduction du culte d'Asclépios que celle d'Amphiaraos » (p. 21) et affirmer par la suite que le culte oraculaire, une fois introduit aux portes de l'Attique, "se serait rapidement enrichi pour répondre aux attentes du moment " (p. 212) pour devenir, in fine, un culte guérisseur principalement ?

Plus objectivement, on regrettera certaines fautes d'accentuation grecque (p. 42:

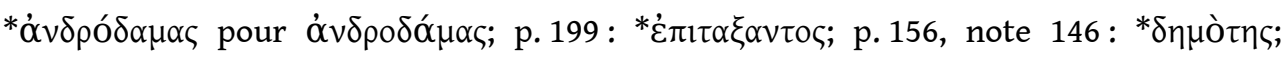

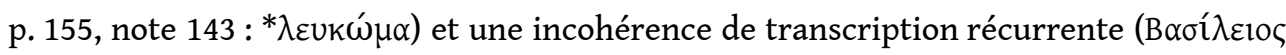

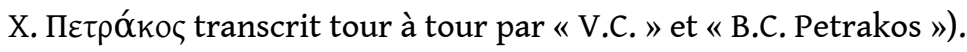

10 Des résumés clairs referment chaque chapitre ou chaque sous-chapitre, au risque d'occasionner quelques redites. Soulignons le grand intérêt de l'index général et des illustrations présentes à la fin de l'ouvrage, qui permettent de visualiser les descriptions de l'A. La bibliographie est fournie et concerne principalement des points qui n'ont pas trait directement à Amphiaraos. Nous avons ainsi affaire à un ouvrage qui, s'appuyant sur de nombreuses sources, propose des pistes de réflexion 
intéressantes, aussi bien sur le personnage d'Amphiaraos que sur différents aspects de la religion grecque, sans refermer totalement certains points de la question.

\section{AUTEURS}

AURIAN DELLI PIZZI

Université de Liège 